\title{
DETERMINAÇÃO DOS PARÂMETROS CINÉTICOS DA REAÇÃO DE TRANSESTERIFICAÇÃO PARA A PRODUÇÃO DE BIODIESEL COM CATÁLISE EM DUAS ETAPAS A PARTIR DE ETANOL E ÓLEO RESIDUAL DE FRITURAS
}

\author{
A. E. DA COSTA ${ }^{1}$, J. K, ANDREAZZA², K. L. HOLEK ${ }^{2}$, M. DA SILVA ${ }^{2}$ e T. K. \\ ANDRIOLI $^{2}$ \\ ${ }^{1}$ IFES - Vila Velha/ ES, Bacharelado em Química Industrial \\ ${ }^{2}$ UNISOCIESC - Joinville/SC, Bacharelado em Engenharia Química \\ E-mail para contato: janaina.andreazza@sociesc.com.br
}

\begin{abstract}
RESUMO - O biodiesel é usualmente obtido por transesterificação de um ácido graxo de cadeia longa e um álcool. É vantajoso produzi-lo com etanol e óleo residual de frituras, entretanto, dados cinéticos para tais condições são escassos, dificultando o dimensionamento do reator. Assim, objetivo deste estudo é determinar a constante de velocidade $(k)$ e a ordem da reação de produção do biodiesel, em duas etapas (catálise ácida seguida de básica), em relação ao óleo e ao etanol. O biodiesel foi produzido em batelada usando óleo residual de frituras e etanol, sob agitação mecânica, usando na primeira etapa como catalisador o ácido sulfúrico, a $50^{\circ} \mathrm{C}$ por 60 min e na segunda etapa usando $\mathrm{NaOH}$, a $70^{\circ} \mathrm{C}$ por 60 min. O teor de éster das amostras foi determinado por cromatografia gasosa. Por intermédio do método diferencial associado ao método dos excessos, determinouse a lei de velocidade para a síntese de biodiesel com catálise em duas etapas. $\mathrm{Na}$ reação de esterificação (catálise ácida) do óleo residual de frituras com o etanol apresenta uma cinética com ordem igual a 1,093 em relação ao óleo e 1,9458 em relação ao etanol, sendo o $k$ de 0,001209 L/(mol.min) e a reação de transesterificação (catálise básica) do óleo residual de frituras já esterificado com o etanol apresenta uma cinética com ordem de 0,6844 em relação ao óleo e 0,3798 em relação ao etanol, sendo que o $k$ de $0,00605 \mathrm{~L} /(\mathrm{mol}$.min). A simulação teve como objetivo a verificação da metodologia aplicada na análise dos dados experimentais.
\end{abstract}

\section{INTRODUÇÃO}

O biodiesel é um combustível de origem renovável que possui grandes vantagens em comparação ao diesel, principalmente no aspecto ambiental. Entretanto, o alto custo do biodiesel o torna menos atrativo comercialmente que o diesel. A escassez de dados cinéticos experimentais com uso de óleo residual de frituras e etanol na produção de biodiesel dificulta a otimização, o projeto de reatores e a previsão do comportamento da reação de produção do biodiesel (GARNICA, 2009).

Segundo Fogler, (2009) a determinação dos parâmetros cinéticos é de extrema 
importância para o projeto de reatores de produção de biodiesel. Obtendo-se a equação de velocidade da reação, as condições de operação e o dimensionamento do reator podem ser determinados para a obtenção da máxima conversão do óleo e do etanol em biodiesel.

Assim, este trabalho teve como objetivo principal determinar a ordem da reação de produção do biodiesel, tanto em relação ao óleo residual de frituras quanto ao etanol, e a velocidade específica da reação, para a etapa de produção com catálise ácida e básica.

\section{MATERIAIS E MÉTODOS}

\section{1. Óleo residual de frituras}

Antes da reação de esterificação, o óleo residual de frituras passou por um prétratamento para a remoção da umidade absorvida no processo de cocção. Sendo assim, em um béquer foram adicionados $1200 \mathrm{~g}$ do óleo residual de frituras $(\mathrm{Mm}=874,8 \mathrm{~g} / \mathrm{mol})$ juntamente de $20 \mathrm{~g} \mathrm{MgSO} 4$ e estes compostos foram submetidos a agitação magnética por $30 \mathrm{~min}$. Após, foi realizada filtração a vácuo para a remoção do sal adicionado e impurezas do óleo residual.

\subsection{Produção de biodiesel com catálise ácida}

A produção de biodiesel por catálise ácida corresponde a uma reação de esterificação, onde o ácido graxo do óleo reage com o álcool utilizando de um catalisador ácido, resultando em ésteres e água. As ordens da reação $(\alpha$ e $\beta)$ e a velocidade específica $(\mathrm{k})$ da reação de esterificação do óleo residual com etanol foram determinadas por meio de uma pesquisa experimental. Foram realizadas 5 reações ao total, sendo triplicata para excesso de etanol e duplicata para excesso de óleo, onde o procedimento é o mesmo alterando apenas a quantidade dos reagentes empregados.

Para a reação com excesso de etanol utilizou-se $1200 \mathrm{~g}$ de óleo residual de frituras prétratado, $378,95 \mathrm{~g}$ de etanol e $6 \mathrm{~g}$ de $\mathrm{H}_{2} \mathrm{SO}_{4}$ como catalisador $(0,5 \%$ em relação à massa de óleo). Para a reação com excesso de óleo utilizou-se $1050 \mathrm{~g}$ de óleo residual de frituras prétratado, $10 \mathrm{~g}$ de etanol e $5,25 \mathrm{~g}$ de $\mathrm{H}_{2} \mathrm{SO}_{4}$ como catalisador ( $0,5 \%$ em relação à massa de óleo).

Após o óleo residual de frituras ser pré-tratado, os reagentes e o catalisador foram pesadas e reservadas. Adicionou-se o óleo e o etanol a um béquer de $2 \mathrm{~L}$ em um sistema com aquecimento e agitação mecânica. Adicionou-se o catalisador com cautela e se iniciou a coleta de amostras.

O meio reacional foi mantido a $50^{\circ} \mathrm{C}\left( \pm 5^{\circ} \mathrm{C}\right)$ e agitação constante durante 60 min. As alíquotas coletadas eram de $2 \mathrm{~mL}$, foram colhidas a cada 5 min do tempo zero a $60 \mathrm{~min}$ (13 alíquotas) e colocadas em banho de gelo para cessar a reação. Decorridos os $60 \mathrm{~min}$, adicionou-se $20 \mathrm{~g}$ de $\mathrm{Na}_{2} \mathrm{CO}_{3}$ para neutralizar a reação e deixou-se sob agitação por $30 \mathrm{~min}$. Para as reações com excesso de etanol, utilizou-se de filtração à vácuo para remover excesso de $\mathrm{Na}_{2} \mathrm{CO}_{3}$ e o sal formado na neutralização.

O excesso de etanol foi removido em um evaporador rotativo com vácuo e, posteriormente, o produto da reação foi colocado em um funil de separação para repousar por, no mínimo, $24 \mathrm{~h}$. Nas reações com excesso de óleo não passam pelo processo de 
evaporação, pois percebe-se pela coloração marrom escura que a reação apresenta, que houve queima do óleo. Por isso, as amostras destas reações são neutralizadas e descartadas.

\subsection{Produção de biodiesel com catálise básica}

A etapa básica corresponde a uma reação de transesterificação, onde o óleo (éster) reage com o álcool utilizando de um catalisador básico e resulta em biodiesel (um éster diferente) e glicerol. Sendo assim, foram realizadas 4 (quatro) reações ao total, sendo duplicata para excesso de etanol e duplicata para excesso de óleo, onde o procedimento é o mesmo alterando apenas a quantidade dos reagentes empregados para a obtenção dos parâmetros cinéticos e lei de velocidade.

Para a reação com excesso de etanol utilizou-se $380 \mathrm{~g}$ de óleo esterificado, $598 \mathrm{~g}$ de etanol e 3,8g de $\mathrm{NaOH}$ como catalisador (1,0\% em relação à massa de óleo). Para a reação com excesso de óleo utilizou-se $380 \mathrm{~g}$ de óleo esterificado, $6 \mathrm{~g}$ de etanol e $3,8 \mathrm{~g}$ de $\mathrm{NaOH}$ como catalisador (1,0\% em relação à massa de óleo).

Inicialmente preparou-se o alcóxido reagindo o etanol com o $\mathrm{NaOH}$ sob agitação constante durante duas horas. Para ser utilizado, o alcóxido repousou por 24h. Para a reação de transesterificação montou-se um sistema idêntico ao montado para a etapa ácida, o óleo foi colocado no béquer de $2 \mathrm{~L}$ e o alcóxido foi adicionado com cautela. $\mathrm{O}$ meio reacional permaneceu sob agitação constante e aquecimento de $70^{\circ} \mathrm{C}\left( \pm 5^{\circ} \mathrm{C}\right)$ durante $60 \mathrm{~min}$., coletando-se amostras de $2 \mathrm{~mL}$ a cada $10 \mathrm{~min}$., a partir do tempo zero até $60 \mathrm{~min}$. Ao serem retiradas, as amostras foram para um banho de gelo para cessar a reação.

Após os $60 \mathrm{~min}$, adicionou-se $20 \mathrm{~g}$ de $\mathrm{Na}_{2} \mathrm{CO}_{3}$ para neutralizar o meio e manteve-se sob agitação constante. Percebeu-se alterações nas reações com excesso de óleo e as mesmas foram descartadas após a neutralização. Já as reações com excesso de etanol foram filtradas em sequência, para retirar o excesso de $\mathrm{Na}_{2} \mathrm{CO}_{3}$ e remover o sal formado na neutralização.

Para que houvesse a separação do biodiesel do glicerol, formados na reação de transesterificação, o excesso de etanol é removido evaporador rotativo e, posteriormente deixou-se o produto da reação em repouso num funil de separação por 24 horas.

\section{RESULTADOS E DISCUSSÃO}

As figuras apresentadas a seguir foram plotadas a partir dos dados tratados de todas as amostras, levando-se em nota que foram realizadas as amostras em triplicata (etapa ácida) e duplicata (etapa básica) e realizado uma média entre cada resultado e sua etapa. Na Figura 1 são apresentados os resultados da aplicação do método diferencial de análise aos dados em relação à etapa ácida.

Assim, pela aplicação do método diferencial dos excessos, verifica-se que a ordem da reação de síntese de biodiesel em relação ao óleo residual é aproximadamente 1. E que a ordem em relação ao etanol é aproximadamente 2, resultando em uma velocidade específica da reação igual a 0,001209 L/(mol.min).

Figura 1 - a) Concentração do óleo residual x tempo de reação, b) Ajuste linear óleo residual, c) Concentração do etanol x tempo de reação e d) Ajuste linear etanol. 

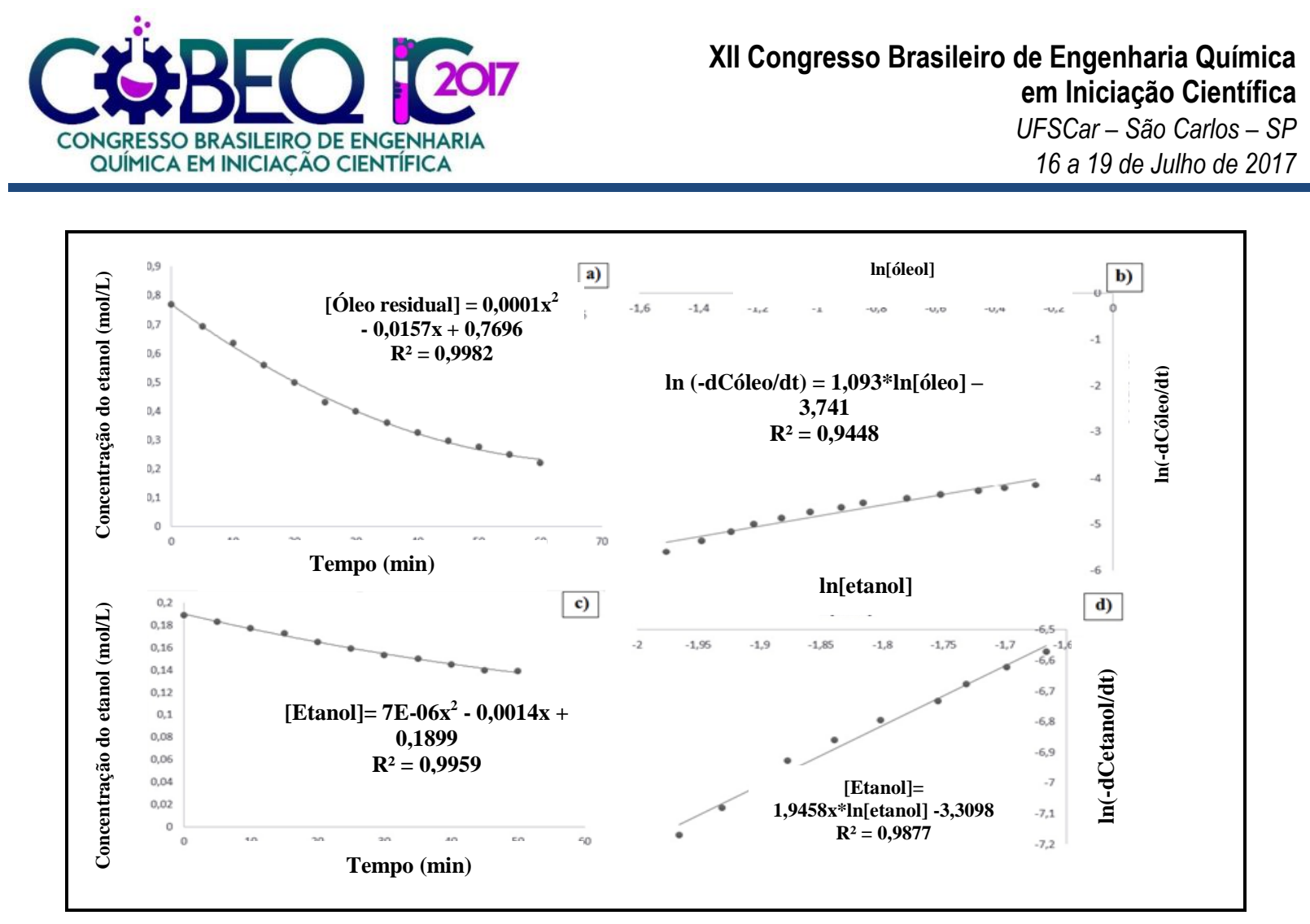

Figura 2 - e) Concentração do óleo residual x do tempo de reação, f) Ajuste linear óleo residual, g) Concentração do etanol x tempo de reação e h) Ajuste linear do etanol

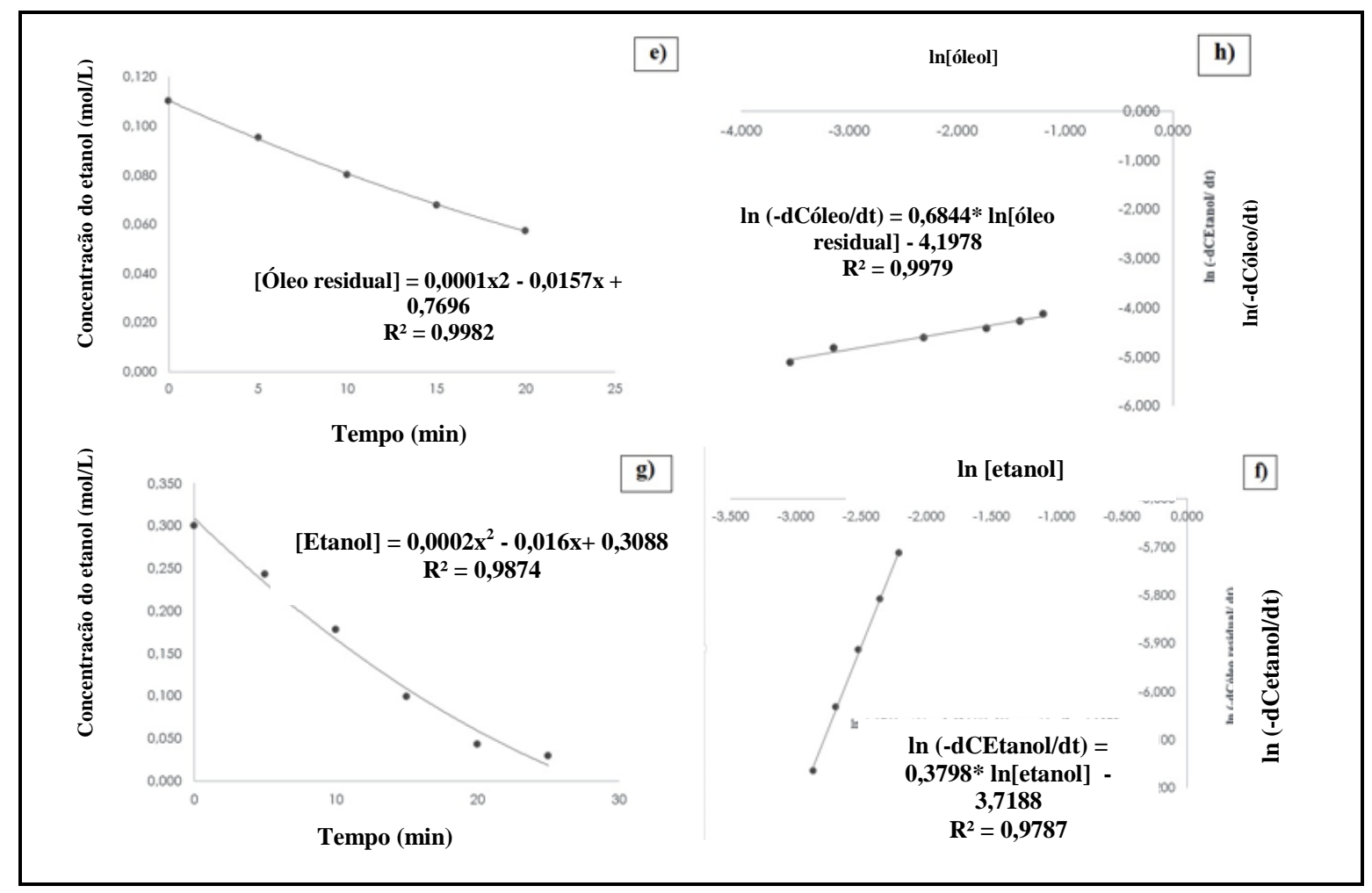

Desta forma, para a reação da catálise básica a mesma seguiu-se a mesma duração da catálise ácida, de $60 \mathrm{~min}$. Contudo, como havia uma porcentagem pequena de óleo residual parcialmente esterificado para dar continuidade à catálise básica, utilizou-se apenas os pontos 
de concentração e tempo de até 25 min para as reações com excesso de etanol e 20 min para as reações com excesso de óleo. Após isto, a reação entrou em equilíbrio e deste modo, não eram representativos para este caso.

Logo, pela aplicação do método diferencial dos excessos, verifica-se que a ordem da reação de síntese de biodiesel em relação ao óleo residual é aproximadamente 0,6844 . E que a ordem em relação ao etanol é aproximadamente 0,3798 , resultando em uma velocidade específica da reação igual a $0,006053 \mathrm{~L} /(\mathrm{mol} . \mathrm{min})$.

Na Figura 2 são apresentados os resultados da aplicação do método diferencial de análise aos dados em relação à etapa básica.

O objetivo da aplicação da simulação computacional nos resultados alcançados experimentalmente é a verificação da metodologia aplicada na análise dos dados. Com o auxílio do programa computacional Matlab (Número de Licença: 271828) é realizado o balanço de massa em reator batelada apenas para o óleo residual, visto que a concentração do álcool varia pouco. Com os parâmetros reunidos (valores das concentrações iniciais do óleo de do etanol no meio reacional; ordem da reação em relação ao óleo e ao álcool; valor da constante da velocidade específica; tempo de reação e número de pontos no tempo) e a equação da conservação da massa solucionada numericamente pelo método de Euler, é realizada a simulação computacional e obtido o gráfico concentração versus tempo.

Nota-se que a concentração do óleo residual foi diminuindo ao longo da reação pois o mesmo estava sendo convertido em ésteres. A semelhança dos Gráficos $1 \mathrm{com}$ a Figura 1 a) e Figura 2 e) respectivamente devem ser consideradas pois, o objetivo era a verificação do método aplicado nos resultados, ou seja, os pontos demarcados na cor azul representam os valores obtidos experimentalmente e as curvas na cor rosa representam as curvas da simulação obtida no Matlab, provando que neste trabalho a metodologia utilizada para a análise dos dados estava correta.

Figura 3 - Perfil dinâmico da concentração: etapas ácida (esquerda) e básica (direita).

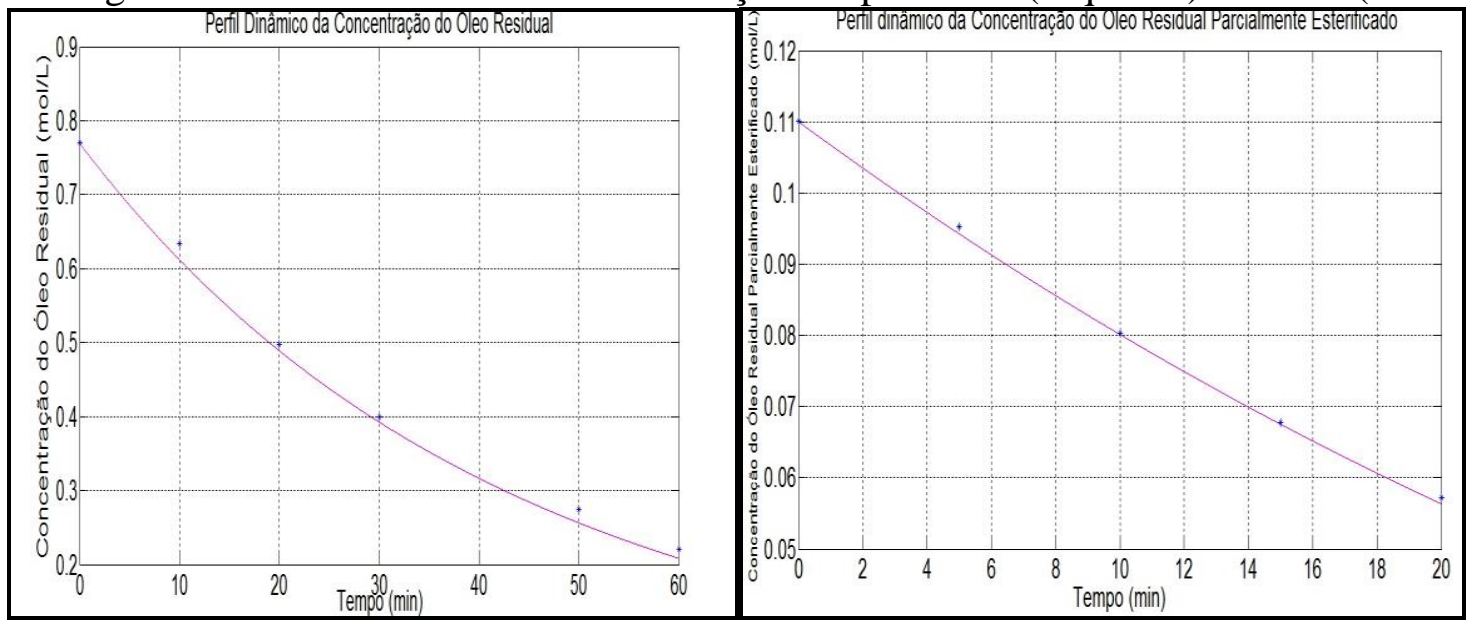




\section{CONCLUSÃO}

Dreher (2014) estudou a determinação da ordem da reação de produção do biodiesel em relação ao óleo de soja e em relação ao etanol, bem como a velocidade específica da reação, por meio do método diferencial associado ao método dos excessos. A reação de transesterificação do óleo de soja com etanol apresenta uma cinética de primeira ordem tanto em relação ao óleo de soja como em relação ao etanol, resultando em uma ordem global igual a dois e velocidade específica da reação igual à $0,00152 \mathrm{~L} \cdot \mathrm{mol}^{-1} \cdot \mathrm{min}^{-1}$.

Zheng et al., (2006) estudaram óleo residual empregando metanol com ácido sulfúrico como catalisador e a transesterificação foi de pseudo-primeira ordem devido ao grande excesso de metanol e a reação se completou em $4 \mathrm{~h}$.

Berrios et al., (2007) estudaram a esterificação de ácidos graxos livres no óleo de girassol empregando metanol na presença de ácido sulfúrico. Os resultados foram encontrados experimentalmente e neste estudo, a reação global foi determinada como uma cinética de segunda ordem.

Observa-se que os resultados do presente trabalho são divergentes dos resultados dos autores citados acima. Este fato dá-se pela dificuldade de se encontrar trabalhos realizados com as mesmas propriedades, ou seja, produção de biodiesel apenas com catálise ácida, empregando óleo residual e etanol. Desta maneira, não é possível realizar uma comparação direta com os autores mencionados. A junção destes fatores, justificam então a obtenção de uma ordem global diferente dos outros autores.

\section{REFERÊNCIAS}

BERRIOS, M.; SILES, J.; MARTIN, M. A; MARTIN, A. A kinetic study of the esterification of free fatty acids in sunflower oil. Departamento de Química Inorgânica e Engenharia Química. Córdoba, Spain, p. 2383-2388, 2007.

DREHER, BRUNA LUIZA. Determinação da velocidade específica e ordens da reação de produção do biodiesel por meio do método diferencial associado ao método dos excessos. Trabalho de Conclusão de Curso. Engenharia Química. UNISOCIESC, 2014.

FOGLER, H.S. Elementos da Engenharia de Reações Químicas. 4ª Ed. Rio de Janeiro: LTC, 2009.

GARNICA, J. A. G. Determinação experimental dos dados cinéticos da reação de transesterificação de óleos vegetais. 2009. 152 p. Dissertação (Mestrado em Engenharia Química) - Universidade Estadual de Campinas, Faculdade de Engenharia Química, Campinas.

ZHENG, S.; KATES, M.; DUBÃ, M. A.; MCLEAN, D. D. Acid-catalyzed production of biodiesel from waste frying oil. Biomass and Bioenergy, p. 267-272. 2006. 